\title{
An Interplay Between Sri Lankan Employees and South Korean Employers: Conflicting Priorities, Attitudes, and Cross-Cultural Perceptions in a 3-D Workplace
}

\author{
Mandari Pabasara Wijerathna \\ Korea University of Technology and Education \\ Gertrude I. Hewapathirana \\ Gulf University for Science and Technology
}

This ethnographic study examined the lived experiences of Sri Lankan 3D workers in South Korea. The purpose was to explore the interplay between unskilled Sri Lankan employees and Korean employers to gain a deeper understanding of critical factors that enhance or hinder optimal performance and to propose HRD interventions to engross expatriate labor meaningfully into host country workplace effectively. The research addressed three research questions. First, what is the type of work relationship prevailed between Korean employers and Sri Lankan workers who engage in 3-D work? Second, what cultural elements are more prominent in their interactions between Korean employers and Sri Lankan workers? And third, what other factors influence the performance of Sri Lankan employees who engage in 3-D work? This paper discovered the hidden realities, factors that obstruct the optimal performance, life experience, and the nature of relationships between Korean employers and Sri Lankan employees in Korean industries. Twenty-one participants who had more than three years of working experience in Korean industries provided rich information that reveals the workplace hidden realities. Emerging themes are presented as five constituents: "attitudes towards Korean bosses and their self," "frustration," "discrimination at workplaces," and "performance barriers." While highlighting critical factors that hinder performance in a 3D workplace, the authors discuss research implications and practice while proposing remedial policy and HRD measures that the Korean and Sri Lankan governments, Korean employers and Sri Lankan 3D workers in Korea would be able to benefit from.

\section{INTRODUCTION}

South Korea (hereafter, Korea), the fifteenth largest and rapidly growing economy in Asia, has been transformed into a multi-cultural, and multi-ethnic society with a huge influx of expatriates adding into the workforce (Kim, 2017). In addition to large scale technology and commercial ventures, flourishing small and medium-sized enterprises, especially, construction, agricultural and heavy metal industries created an increasing demand for low-skilled workers to carry out 3-D (dirty, dangerous and difficult) work. However, after achieving high economic development, and changing lifestyles, native Koreans are no longer willing to do '3-D jobs' even though they are offered comparatively higher wages. Because of 
native Korean workers' changing attitudes towards 3-D jobs, the Korean labor market suffers from a labor shortage in manufacturing, agriculture, heavy metal and construction industry sectors where there is a high demand for unskilled workers (Abella, Park, \& Böhning, 1994). A severe labor shortage is in the above-mentioned small-scale industry sectors to carry out 3-D jobs (Abella, Park, \& Böhning, 1994; Kim, 2017). To support domestic industries to keep up with the growing economy, the Korean government started issuing a work visa to attract cheap labor from nearby developing countries. Thus, increasing demand for cheap expatriate labor has become an essential alternative to meet the increasing needs of growing industries.

To keep up with the economic growth trend, Korea attracts long-term and short-term expatriate cheap labor from 16 neighboring countries, including Bangladesh, Vietnam, Thailand, Philippines, and Sri Lanka. Over the last decade, the Korean economy attracted all levels of expatriate workers under the Employment Permit System (EPS) and international marriages (Kim, 2009; Park, 2007). South Korea was planning to receive 42,300 expatriate "workers in the manufacturing sector, 6,600 in the agricultural industry, 2,600 in the fishing sector, 2,400 in the construction sector and 100 in the service sector on E-9 visas" in 2018 (Hyun-ju, 2017, p.1). It is estimated that to remedy the increasing labor shortage, Korea needs to attract an estimated number of 100,000 expatriate workers annually between 2030 and 2050 (Seol \& Han, 2004, p.46). A vast influx of multi-cultural workforce resulted in workplace complexities and cross-cultural conflicts. Thus, organizational and managerial readiness to engage low-skilled multicultural employees meaningfully into Korean organizations has become a significant concern. Therefore, this research aims to explore emic realities of individual values, life, and work priorities, attitudes, perceptions towards 3-D work, cultural and contextual factors in Korea's 3-D workplace with the intention of providing our insights for concerned parties and human resource practitioners. For this purpose, we carry out an ethnographic study to understand the interplay between unskilled Sri Lankan employees and Korean employers to gain a deeper understanding to learn how to utilize expatriate labor meaningfully in a host country workplace. The following sections include a review of the literature, the problem, purpose, and the research methods, the context of the study, and findings followed by a discussion and implications.

\section{LITERATURE REVIEW}

\section{Individual, Organizational and National Cultural Factors that Affect Expatriate Employees}

Living and working in a foreign country where the organizations offer short-term or no training to orient expatriates and integrate them into a new work culture is challenging (Albrecht, 2000). Garrod (2005) found that increasing expatriate employees in an Indonesian workplace resulted in conflicting work behaviors, and values, cultural misunderstandings and hostile work attitudes. Conflicting work and life priorities and lack of cultural understanding have been discussed as critical impediments for optimal work performance in host country workplaces (Yi, 2013; Kim, 2009). A study of Korean workers in Indonesia found that employees who did not have a good understanding of the host country culture resulted in low self-confidence and low-self-esteem than personal values (Frendika, Sule, Kusman, \& Jeoelty, 2018). Cross-cultural conflicts arise due to differences of beliefs, attitudes, values among people from different cultures and nations (Hofstede \& Bond, 1988) and low self-esteem due to negative thoughts of self-image also creates a low performance in a new culture (Kim, 1992). Cultural competence is the ability to integrate and transform knowledge that builds mutual trust among individuals (Seba \& Rowley, 2010). Gudykunsts \& Kim (1992) found that cultural communication because of an individual's personality orientation, self-construal, and individual values and communication is an essential instrument for gaining clear cultural understanding.

Per Cateora, Graham, \& Gilly (2013) culture is the "sum of values, rituals, symbols, beliefs, and thoughts processes that are learned and shared by a group of people" (p.102); Martin \& Nakayama (2014) describe culture as "a key site for the formation of identities, for the way in which we make sense of the world and locate ourselves within it" (p. 215). Further, they say that "to maintain our identities, as well as to reshape them, we often turn to popular culture" (p. 215). People represent several groups, and the 
influence of the culture forms the identity of individuals (O'Neil, 2006). Conflicts occur between individuals or groups when there is an incompatibility of life and work goals, values, expectations, processes, and outcomes (Martin \& Nakayama, 2014).

Rozkwitalska (2009) describes that cultural and contextual factors become barriers at individual and organizational levels as they create "cultural distance, cultural shock, cultural stereotypes, prejudices, and national ethnocentrism (p.128)." At an individual level, attitude, perceptions, individual characteristics, motivation, skill, knowledge, individual abilities, and level of understanding of the host culture often creates conflicts while at organizational level organizational characteristics, organizational culture, and managers understanding and ability to integrate and find organizational solutions become critical factors.

\section{Expatriate Employee Performance}

In an organization, employees are the primary resource (Luthans \& Stajkovic, 1999). Organizational performance, on the other hand, equates a sum of employee performance (Collis \& Montgomery,1995). Deadrick and Gardner (1997) defined employee performance as a result of the employees' achievement. According to Whetten and Cameron (1998) employee performance is a product of motivation. Herbert, Donald, John \& Lee (2000) state that employee performance is the outcome of achieving employee's goals. Active engagement of employees and mutually beneficial work relationships (cooperativeness) among all players in an organization ensure quantity, quality, and timeliness of achieving output goals (Gungor, 2011).

McCloy, Campel, and Cudeck (1994) cite that 'declarative knowledge,' 'procedural knowledge,' and 'motivation' as the critical ingredients of employee performance. On the contrary, As cited in Malik, Awais, Timsal, \& Qureshi (2016), Carlson, Kacmar, Wayne, and Grzywacz (2006), "projected training and development, compensation level, maintain morale, recruitment package and performance appraisal, as the five dimension of human resource practices that enhance performance" (p.591). Truong (2012) states organizational culture, leadership, communication, and working environment impact on employees' performance. As per Muda, Rafiki, and Harahap (2014), job stress, communication, and inspiration are the factors affecting employees' performance. Saeed, Mussawar, Lodhi, Iqbal, Nayab, and Yaseen's (2013) found that worker's problems, job situation, attitude, and rewards have a positive impact on employee performance. Likewise, several researchers discuss factors that affect employee performance at individual, organizational, contextual, and national levels.

\section{The Problem}

A vast number of cross-cultural workplace research on what factors boost employee performance and commitment have been conducted using participants in the skilled category and management positions. However, there is a dearth of research to understand what factors make higher work outcome of unskilled labor category (Harrell-Cook, Levitt, \& Grimm, 2017). Per Republic Korea's National Human Right Commission (2013), expatriate employees in Korea are experiencing multitudes of problems such as workplace discrimination (84\%), verbal abuse (76\%), physical assault (15\%) and an innumerable number of much more hardships. Work-place related injuries, illnesses, and unfavorable work conditions have been reported frequently; language barriers, a high cost of healthcare, failing to get employers permission, inability to get sick leave are a few examples of critical factors that make difficult for expatriates to fully function in Korean organizations. Due to rigid immigration policies and restrictions, expatriates are unable to change jobs without the employer's permission. Their work contracts can be terminated without justification, and lead to deportation (Kim, 2017). Thus, expatriate workers become vulnerable to job loss and challenging to balance their work and family life.

\section{The Purpose of the Study}

The purpose of this ethnographic research is to gain an emic understanding of hidden factors, life experience and relationships between Korean employers and Sri Lankan employees who are engaged in 3 -D work in Korean industries using the following research questions. 
(a) What is the type of work relationship prevailed between Korean employers and Sri Lankan workers who are engaged in 3-D work?

(b) What cultural elements are more prominent in their interactions between Korean employers and Sri Lankan workers?

(c) What other factors influence the performance of Sri Lankan employees who engage in 3-D work?

\section{The Context of the Study}

Because of higher wages, Korea became a dream paradise for most unskilled workers in developing countries. The government regulates the employment of expatriate workers in Korea through the Employment Permit System (EPS) introduced in 2004 (Library of Congress, 2015). Unskilled workers are categorized as unskilled workers (E-9 visa) under the EPS which comprises almost half of the total migrant workforce. Migrant workers are granted to work only in small and medium industries just for four years and eight months (Pak, 2006), and there are 1,467,873 total registered foreign workers (Republic of Korea Ministry of Justice, 2017).

Under the EPS employment quota system, Sri Lankan workers account only for $6 \%$ of total immigrant workers. Current year, Korea employed 276,166 unskilled workers, and among them, 25,099 are Sri Lankans. Thus, each year approximately 5000 Sri Lankan low skilled workers arrive in Korea.

Additionally, there are undocumented expatriate workers, and approximately 1500 of them are Sri Lankans. Those workers who come under EPS Visa are required to participate in the pre-departure training for EPS job seekers which includes a brief introduction to the Korean language, industrial safety, and EPS system. Due to no or little Korean language skills, Sri Lankan workers rarely mix with native Koreans; therefore, these workers often live in isolation.

\section{RESEARCH METHODOLOGY}

Based on the purpose of this research and the research questions, an ethnographic method was chosen to uncover hidden realities of work-related behaviors, attitudes and the nature of work relationships of Sri Lankan workers who are engaged in 3-D work in Korea. Ethnography describes the behaviors, relationships, ideologies, and factors that delineate communities (Wolcott, 1999). Creswell (2007) states, "Ethnographers study the meaning of the behavior, the language, and the interaction among members of the culture-sharing group" (pp. 68-69). Ethnography is about description of social realities to gain an emic consideration from the participants' perspectives involved in a social group (Parker (2005); field notes help to record emic data (Holt \& Sparkes, 2001). Ethnography facilitates studying a small group of people's work, interests, attitudes, rules, patterns of engagement and lived experience (Holt \& Sparkes, 2001; Wolcott, 1999); ethnography describes the relationships, behaviors, and factors of a cultural group (Lofland \& Lofland, 1995) during a specific period to assemble data through observation (Madison, 2005).

In an ethnographic study, data can be collected throughout a specific period and can use a variety of methods such as observations, interviews, intermingling with social and family events, collecting related artifacts, storytelling and so on (Creswel, 2007). Throughout the study, notes were taken, and taperecorded conversations and interviews and transcribed and analyzed (Hammersley \& Atkinson, 1995). A critical analysis enables a researcher to understand hidden realities of a culture (Crotty, 1998) because ethnography "unmasks hegemony and address[es] oppressive forces" for a societal transformation (p. 12). The purpose of ethnography is to discover the social, cultural, or normative patterns of a group of people (Holt \& Sparkes, 2001). Ethnography also supports collecting participants' lived experience. Since the current study aims to explore Sri Lankan workers' lived experience, life and work priorities, viewpoints, relationships, behaviors and attitudes toward their employers and how such life experiences impact on their job performance, ethnography is chosen as an appropriate method of this study. 


\section{Participants}

The researchers are Sri Lankans who can carry out conversations with participants in their native langue to understand emic perspectives and cultural meanings and have connections to many Sri Lankan families and employees in Korea. Sri Lankan workers who worked in Korea for a minimum of five years were selected as they have substantial work experience in 3-D workplaces and who can provide rich information. A snowballing sampling method (Noy, 2008) was used to connect with friends and their friends.

Additionally, personal connections, references, work records, and those who attend the Sri Lankan family and social events were invited. Initially, 30 Sri Lankans who engaged in 3-D work was invited to participate. The data were gathered from 21 participants who had time and gave consensus to participate. Among the 21 participants, nine workers are working in the production sector, nine in the manufacturing sector and three participants from fisheries volunteer to participate in the study. Before meeting them, the participants were informed of the purpose, the nature of the research, time duration, and their commitment to allow the researcher to participate in various events. They were assured their participation is voluntary; their participation in this research will not be a threat to their work or performance evaluations in Korea as the data is strongly confidential.

TABLE 1

THE LIST OF THE PARTICIPANTS

(NAMES ARE ANONYMOUS)

\begin{tabular}{lllll}
\hline \hline No. & Name & Age & Occupation & Province \\
\hline 1 & Nelum & 27 & Production & Ansan \\
2 & Sethunga & 29 & Manufacturing & Daegu \\
3 & Uditha & 37 & Production & Pusan \\
4 & Nishanthi & 37 & Production & Ansan \\
5 & Upuli & 29 & Manufacturing & Cheonan \\
6 & Rupe & 38 & Fisheries & Chejudo \\
7 & Chanaka & 28 & Manufacturing & Ansan \\
8 & Melan & 34 & Production & Daegu \\
9 & Kanushka & 33 & Manufacturing & Ansan \\
10 & Fernando & 32 & Production & Ansan \\
11 & Buddhika & 39 & Manufacturing & Daejon \\
12 & Sisira & 33 & Manufacturing & Cheonan \\
13 & Rupe & 32 & Production & Ansan \\
14 & Harshani & 37 & Manufacturing & Daegu \\
15 & Saumya & 29 & Production & Incheon \\
16 & Nadeesh & 34 & Production & Cheonan \\
17 & Nuwan & 23 & Manufacturing & Daegu \\
18 & Bimsara & 29 & Fisheries & Chejudo \\
19 & Adesh & 36 & Manufacturing & Ansan \\
20 & Dammika & 27 & Fisheries & Chejudo \\
21 & Nimalasiri & 38 & Production & Incheon \\
\hline \hline & & & & \\
\hline
\end{tabular}




\section{Methods of Data Collection}

The researchers collected data from participant observation, personal communication and interviews, documents/artifacts, and attending participants' family and social events. Semi-structured interviews (Merriam, 1998) were conducted during April 14, 2017, to June 21, 2018. Throughout the study period, the participants were contacted by phone and Skype to get their consensus and locating family and social events and to set times for interviews. Before conducting face-to-face interviews, the researchers spent time with the participants attending family and social events. The first author has worked in the HRD service of Korea as the in charge of Sri Lankan workers; she spends time with these workers sharing lunch and coffee to become familiar with them. Semi-structured interviews were conducted in a highly confidential manner in places convenient for participants such as coffee shops, dormitory lobby, temple, and church. Each interview lasts two to three hours. The interviews began with a brief discussion of the purpose of the research process, and participants were also welcomed to ask questions at any point during the interview process. The participant's feelings, critical incidents, and their opinions were revealed through their stories. To find additional information, Skype interviews were conducted, and conversations were recorded with the permission of the respondents.

\section{Data Analysis}

An analysis in ethnographic studies is a reflexive activity that starts with open-ended research questions with probing questions to uncover deeper meanings and continue throughout data generation to a final documenting stage (Hammersley \& Atkinson, 2007). Wolcott's (1994) three-step processes for ethnographic analysis: description, analysis, and interpretation were used. Ethnography is an interpretive act and to explain the interpretation, and it is first essential to describe the culture of the study context. The researchers documented everything they observed. For example, the researchers took additional notes about the surroundings, feelings, emotions, organizational routines, practices, and policies using a variety of methods such as diagrams, pictures, and narrative explanations. Field notes also include chronological narrative accounts of the experiences, stories, and critical incidents.

As per Bogdan \& Biklen (2007), each meaning unit was assigned a specific coding system; Green \& Thorogood (2013) describe breaking into specific meaning units and assigning codes as thematic analysis. In the analysis process, all the interview data and field notes were transcribed and read multiple times to understand the meanings and categorized into meaning units.

\section{Trustworthiness of the Data}

Creswell (2007) recommends that a minimum of two types of verification be completed to ensure the trustworthiness of qualitative research. In the current study, trustworthiness is established through triangulation of data from a variety of sources such as interviews, observations, documents, artifacts, critical incidents, and stories collected throughout the study period. Triangulation of data authenticates and checks whether the findings are reflecting what the participants have described during the data collection process (Yin, 2003). To cross-check whether the participants' ideas are reflecting in the themes, researchers contacted them multiple times throughout the analysis phases.

\section{FINDINGS}

The findings have been presented as emerging themes and were categorized into four major constituents as "employee attitudes towards Korean bosses," "frustrations, frictions and hostilities," "discrimination at the workplace," and "barriers to performance." Much of the emerging sub-themes revealed deeply rooted frictions, hostilities, frustrations, separations, mistrust, conflicts, hostility, confusions, conflicting work behaviors and work priorities between Korean employers and Sri Lankan 3D workers. A few of the participants reflected on positive work relationships between Korean bosses and Sri Lankan employees. The following are a summary of findings under each major theme. 


\section{Attitudes Towards Korean Bosses and Their Own Self}

The 21 participants expressed their attitudes towards Korean bosses, workplace, and Korean work ethics as follows.

\section{Frictions and Hostilities at Work}

Participants had indifferent views towards their Koran bosses. From the participants' views, Korean bosses treat their workplace as their property while Sri Lankan 3-D workers were treated as strangers and outsiders. Such uncaring behavior has been expressed as "Koreans in my company consider company as their own family and life... we also have our own families, and we want to feed our family. That's why we work. Even if we work hard, all the profit goes to the boss's bag. Personally, I do not have any bond with the company..." (Participant 3). All the participants believed that Korean bosses do not care about employees, their work-life, and wellbeing. Thus, participants have developed frictions and hostile attitudes toward their bosses.

\section{Conflicting Work Priorities}

There were conflicting work and life priorities. Conflicting priorities invariably created frictions as well as a psychological separation between Korean bosses and expatriate employees. Their inner selves have been further expressed:

Koreans sacrifice their whole life to their companies. They have no personal life...They treat their peers (co-workers) as family...eat together, drink together... But we are treated as outsiders... Why should we work like this? We came to Korea to earn money to feed our families. We work hard during working hours. But after working hours, we need to spend our leisure time with our families (Participant 6).

\section{Conflicts Between National Cultural Practices and Work Culture}

Participants expressed their bosses want them to be trustworthy, punctual, work fast and hard without a break, and carry out extra work without pay. Participant 11 said that to understand this work culture he took a long time because there was no orientation to learn about workplace culture. They learn by observing and experiencing in a hard way. Nine participants said that they are not used to work on time. As they said, "In Sri Lanka, time is not so important as compared to employee family and wellbeing. It doesn't matter if we come two or three hours late... we used to give so many excuses like trains are late... bus strikes... But here in Korea, it is challenging for us to use this way of doing things. Korean workers go to work one or two hours before the working hours. In the annual performance valuing day, I received the last place because of this." Participants said that they couldn't understand Korean group-work concepts. "If one works hard and complete the workload faster, boss assigns more and more work without rewards. Korean workplace is different..."

In the company, we were given group targets, not individual targets. If we work hard only, the team leader is appreciated... I hate group work system because individual members do not have any gains or rewards. (Participant 13)

Participant 5 explained how his boss slapped him when he was having a rest for five minutes:

I'm operating a machine where I feel very hot. I need to take a five-minute break at least every three hours...But my boss thinks that my five-minutes break will decrease the quantity of productions. Whenever I want to take a rest he says, "palli palli" (quickly, quickly) ... why can’t you work palli palli? And he slapped me for this.

Thus, participants viewed that they are being treated as machines rather than humans. All the participants disclosed their unpleasant work experience and barriers to performing. Six workers explained 
similar cross-cultural clashes they faced when working with other employees from Mongolia, Uzbekistan, Vietnam, and the Philippines.

\section{Increasing Cynicism with Paranoid Employers}

Participants have deeply rooted beliefs that their bosses do not trust their abilities because Korean bosses think that Sri Lankans are lazy and do not work hard when the boss is not watching. Stereotypical attitudes have been revealed as "my boss is always keeping an eye on me. He thinks that I work hard only if the boss is watching... So if he goes out to meet his business partners or suppliers, he asks his wife or son to come and be in the factory" (Participant 20). Seven participants stated that their bosses are watching their every movement through CCTVs because of the fear that they will rob and sell the goods to the other suppliers secretly, "...because we are poor, Korean bosses think we try to get money by stealing" (Participant 9). Workplace distrust has become an impediment to building trustworthy work relationships; thus, stereotypical cultural attitudes have created frictions between employees and their bosses.

\section{Unethical Practices}

Five participants explained their bosses do unethical practices. For example, their bosses listen to their every phone and other conversations because their bosses think that these workers will escape or move to other companies.

My sajannim (boss) always reminds me that he paid his 'blood like money' for my airtickets and basic training courses...I do not have the right to move or break the work contract...As he said I'm like his cow borrowed from another person for five years... my life belongs to my boss. (Participant 8 )

These expressions evident deeply rooted mistrust between employers and employees. Such mistrust has not only separated Korean bosses from Sri Lankan 3-D workers, but it demoralizes employees.

\section{Feeling of Uncertainty and Fear of Losing Jobs}

All the participants expressed their feelings of uncertainty in their jobs. In addition to mistrust, work conflicts, hostile work environment, and feelings of exclusions created a constant fear of losing their jobs. Such anxiety has been observed as "We don't know what will happen tomorrow..." (Participant 3) "Koreans are changing with no time." (Participant 11). Participants have deeply held a belief that hires, and fires are common practices in Korean companies. Among the participants, few employees were fired from their previous workplaces without any justifiable reason:

I worked in the OO company for seven months. One morning my boss called me and he gave me, an envelope and asked me to find another job immediately. I was fired!!! I couldn't imagine the reason. How can I find a job in Korea alone? I asked the reason, and my boss said he does not like my face...I'm trembling every day whenever my new boss asks me to come and meet him. Who knows whether he is going to fire me again? Because of this tension and fear I can't work hard...I may be fired tomorrow..." (Participant 14)

\section{Moral Dilemma}

All the participants realized that showing loyalty to the boss and the company is highly valued by Koreans as they call, "our company, our boss" whenever they address boss or company. To show this loyalty, participant 5 said that he pretended to work hard without taking a rest. Out of the 21 participants, only those who demonstrated loyalty got their contract renewed for another four and ten months. Participant 8 said: 
I showed my boss I am ambitious, honest, obedient, and willing to follow his orders at any time and love to work with him through my every movement and words...he is nothing but like my father to me now...he invites me to his home and joins with his family on family occasions and Korean festivals... If you win your boss, you can work for them till you die...

Participant 11 said that his salary was increased within a few months due to his obedience to the boss. Participant 2, 5, and 12 also said that if they show loyalty to the boss, he doesn't hesitate to pay incentives. Likewise, some participants made an effort to win their bosses to be in their good books.

\section{Stereotypical Attitudes}

Participants believed their bosses are unwilling to change as they stick to old passion traditional values. Participant 10 stated:

In our workplace, everything is done according to traditional systems. Boss told us that these old systems were made by his late grandfather and he likes to follow him. So, he does not like to buy new production machines, and everything is done manually. I thought he is afraid of new technology... My boss believes that if he changes the old methods used by his ancestors, his ancestors will get angry with him, and everything will be destroyed...

Thus, stereotypical beliefs and attitudes of their bosses have been viewed by the participants as obsolete work practices in a new world. Participant 4 stated that Koreans do not like to work for female leaders; thus, gender discrimination in the workplace has been revealed.

\section{Frustrations}

"Frustrations" were endorsed by all the participants. Due to ongoing frustrations and disappointments, participants demonstrated a higher level of dissatisfaction in their workplaces. The sub-constituents emerged as "no promotions," "lack of safety and welfare," and "different worlds." There were frustrations as their bosses do not recognize hard work and no tangible monitory rewards or appreciations.

\section{No Promotions}

Participant 4 said, "I have been working in the same company for eight years. I'm still in the same position...My Korean juniors have now become supervisors. Likewise, participants felt hard work does not bring any rewards. Six participants explained that it is difficult for them to get promotions because they are foreigners. Thus, workplace separation between employee and employer has been observed.

\section{Feeling of Exploitations and Lack of Motivation}

Six participants expressed that they were assigned unachievable daily workload and targets. Even if they worked hard and completed the daily workloads five minutes before the off-hours, the boss assigns them more work which cannot be completed within two or three hours. Thus, participants work long hours daily without extra pay for their extra work hours. Participant 11 stated, "I feel I'm like a machine. Sometimes I work for 24 hours non-stop. No rest, no foods...work! work! work! You see even a machine needs oil and free time. I don't know why sajannim (boss) can't understand this?." These expressions highlight their inner frustrations and feeling of exploitation. These workplace hostilities have become sources of mistrust, thus thriving frustrations.

\section{Lack of Safety and Welfare}

Participants felt they are working in an unhealthy work environment without proper sanitary facilities. Seven Participants explained that they are living in small containers and some of them share one small room with four or five others. 
I'm living in a container home where I met with several accidents in winter due to electric leek. Eight workers are living in the same room where we can't rest or learn the Korean language. When one of us talk to our family in our country, all of us can hear and no privacy (Participant 4).

Participants explained the workplace hardships and employers' lack of concern for employees' safety. Participant 10 explained:

There is no value for our lives in Korea. I lost my finger...some of my friends died while working. Sajannim doesn't allow us to take a rest even for five minutes. They care about their dead cows more than us... We work like cattles from dawn to dusk... to earn money to feed our kids.

Thus, employees' frustrations, unhealthy work environment, and the feeling of self-unworthiness have aggravated employee's frustrations.

Indifferent Treatments and Lack of Cultural Sensitivity.

All the participants said their bosses could not understand why they do not eat Korean foods, especially kimchi (Korean cabbage pickle). Bosses are asking them, "If you come to Korea you must eat Korean foods" and giving them cheap Korean foods which they do not even look at. Participant 8 stated, "Actually I was afraid of eating together with them, as we know that Koreans eat dogs and serpents...I'm afraid that they put dog meat in a stew. When I reject the foods, my boss blamed me for wasting foods. Because food is his money.....as he told." Though Korean bosses treat their expatriate employees indifferently, their bosses are living in luxury homes and value their safety and health. Participant 3 expressed his frustrations and hatred towards those who have luxury lives as "sanitary facilities, limited works, holidays, resting time... those are fancy talks which are only limited to books and curriculums." Seventeen participants said that when some employment agents who are dealing with them come to check their living conditions, their bosses give them black money (bribes) or gifts and send them back, "We are foreigners in a foreign country. No one is ready to hear our stories...Koreans take Koreans' side..."

\section{Discrimination at the Workplace}

Workplace discrimination has been revealed as participant 1 explained how his boss treats all the foreign workers in a disgraceful manner: "Every day we get rice with kimchi or kimchi with rice while the other Korean peers get different foods. We are not allowed to sit at their tables. We do not have the energy to work as most of us do not like even the kimchi nemse (the smell of cabbage pickle).

All the participants stated that their bosses call them "stupid Lankans," "dogs (keseki)" for talking with his family over the phone during working hours. Participant 13 said that his boss gave him ragged clothes and shoes and said "These clothes are good enough for you...made in Korea! Made in Korea!." Participant 5 noted how his samonim (boss's wife) treated him as a savage when he used his hand to eat because he was not familiar with using chopsticks. Participant 12 explained that all the young Korean workers speak in panmal (low form of spoken language) to him, which is strictly not allowed in Korean society. Fifteen participants described their anxiety about being treated by their bosses as uncivilized outsiders in their companies. Female workers explained that most of their duties in the workplaces are preparing foods for other workers. Participant 14 said, "I work similarly with all the other male workers, but I was taught that my duty is also to make coffee and rice to the staff. Whenever the workers ask for coffee, I must prepare. Everyone has hands why can't they do their works by themselves? If all receive the same salary, why should I make coffee?"

"Dark-skinned Foreigner"

This subtheme uncovers physical and mental harassments these employees face in their workplaces due to xenophobia. Participant 8 expressed: 
I was advised not to come in front of my boss in the early morning because my dark skin will bring him lucklessly (jesuga obta). I'm not allowed to touch the new machines or vehicles because of my dark skin...

Female workers were discriminated against as they were treated as subordinate to male peers. Female participants were expected to work as helpers of male employees.

I have completed a welding course at 00 in Sri Lanka, and I have ten years of working experience. But our sajannim (boss) does not allow me to do welding works. What he says is women have no ability to do such works and asks me to follow the orders of males.

Thus, gender discriminatory attitudes have become a stumbling block to achieve the full potential of female employees.

\section{Prejudice Towards $3 D$ Workers}

All the participants expressed a loss of work expectations. The type of work they expected to engage in Korea and what they are assigned to do are different. Participant 10 said that his boss always discourages him.

Our sajannim always reminds me that I came from a third world country and I came here to work because I'm poor. He condemns my country, my culture... Whenever I hear those discriminatory words, I feel helpless, and it creates a wound in my heart, and my wound is becoming bigger and bigger daily. It is difficult for me to work in Korea, eat Korean foods, and separation from my family and friends...I do not like to work...I'm impatient till I finish my contract period before being released from this prison...

\section{Barriers to Performance}

Lack of Confidence and Encouragements

Participants expressed that they are not evaluated justly even though they work hard. Participant 5 stated that he is wondering whether he did his work accurately or not because the boss says nothing. Participant 17 explained that even though they work hard to their maximum potential, their bosses ignore by saying, "work more, work more... you need to work more." Participant 15 stated:

...Korean bosses do not appreciate our work. They look down towards us. Even if we do our best, they do not care... We came to earn money and learn skills for our future. But what we bring back is just pain of an incurable wound.

\section{Lack of Training}

Four participants stated that they start working in their companies where they never received any proper training and their bosses ask them to learn from the native Korean seniors. Participant 7 stated:

I was asked to operate a cutting machine without any training. Sajannim (boss) appointed me under a native Korean senior worker, and when I went to him on the first day he screamed like 'Oh! weguk in nemse!' (bad smell of a foreigner). How can I get rid of the foreign smell of mine? When I was standing near the machined sajannim blamed me, and I remembered my kids, wife, and old mother. So, I started operating the machine by myself and cut my two fingers. Now I'm handicapped forever... (crying). 


\section{Lack of Language Skills}

All the participants said that neither their bosses nor the line managers could speak English and they are facing difficulties communicating without Korean or English language skills. All the instructions are delivered in Korean. Due to a lack of language skills, employees face difficulties in understanding work processes.

\section{DISCUSSION, IMPLICATIONS, LIMITATIONS, AND CONCLUSION}

The purpose of this study is to explore emic realities of Sri Lankan employees work and life experience, priorities, attitudes, perceptions, cultural and contextual factors in Korean 3-D workplace with the intention of providing our insights for concerned parties and human resource practitioners. The researchers uncovered some of the critical factors that hinder or enhance expatriate employee performance in a host country 3-D workplace. The findings were categorized as conflicting attitudes, inner frustrations, workplace discrimination, and barriers to optimal performance. These findings reinforce Arsene's (2014) and Ahmad's (2008) findings that living and working in a foreign country is challenging as all the participants in this study reported Korean bosses "do not trust our skills," "keep an eye on us," and "abusive." Unfamiliar work practices and processes due to lack of training has become an impediment. Langue plays as the main barrier in living and working in Korea, and our findings are consistent with Masson and Guimary (1981) and Mines and Martin's (1984) studies where the unskilled workers appear to be ardent and, our research exhibits the unrevealed picture of unskilled workers in South Korea.

Ongoing workplace conflicts have become obstructions to performance while frictions between employer and employees have aggravated disloyalty. Frustrations, lack of job stability, discriminatory attitudes, and prejudices towards foreignness hinder effective performance. These findings are congruent with the findings of Arsene's (2014) study on Ugandan workers who work under Chinese bosses.

Korean work culture is heavily influenced by Confucianism ideology, while Sri Lankan work culture is shaped by Buddhist values. Korean workplace focuses on group work rather than individuals. It is revealed that in Korean 3-D workplace, foreign workers have been discriminated as they hardly accept foreigners as their in-group members or peers. In this study, foreign workers are considered as outsiders to their workgroups. This exclusion from peer groups diminishes loyalty to the boss as well as the company, thus negatively affecting employee performance.

Our study discovered ongoing hostilities, preconceptions, and animosity towards foreign workers. These findings are consistent with Seol's (2005) study that Korean employers hire foreign workers for unskilled jobs because they are cheaper than native workers. Low waged, low skilled employees suffer from discrimination, physical and mentally abusive behavior in workplaces. Being natives of developing countries in a host country has become a cumbersome experience because Korean bosses treat these 3D workers unfairly, harshly, and badly (Seol \& Han, 2004). Employers consider migrant workers as "servants," "farmhands," or "maids" who became their property. Seol, Choi, and Han's (2002) identified $51 \%$ of the migrant workers experienced "verbal abuse and ridicule" at their workplaces. Our findings establish the fact that that South Korea needs to adopt efficient human resource practices to utilize lowskilled expatriate employees to achieve their organizational and national economic objectives.

Our study suggests that Sri Lankan migrant workers, prior to or after they arrive in a host country, need rigorous training, mutually congruent attitudes and expertise in building relationships. Learning host country work ethics, cultural practices, and language skills are vital skills for employees to sustain in a foreign country.

Ignorance of cultures, employee expectations, life, and work priorities of migrant workers have become huge skill gaps of managers or supervisors (Curtis \& Lucas, 2001). Binder (2007) agrees Gilbert's (1978) view "when training was introduced into environments in which other behavioral influences were lacking or in conflict, it was seldom cost-effective. [It became clear that] for performance to accelerate and maintain, it was necessary to manage a broader range of variables and conditions" (p. 7). 
Our findings are consistent with Najeeb (2011) and Anderson (2010) studies as we discovered that unskilled migrant workers in Korea are experiencing unsafe work environment, harassment, ill-treatment, discrimination, and cultural clashes. These migrant workers suffer from non-payment/ underpayment, unhealthy living and work conditions, unlimited working hours, food destitution, and various physical and psychological abuses.

This research indicated how Gilberts (1978), Behavior Engineering Model (BEM) helped in diagnosing issues and solutions. BEM is a viable tool to detect performance diminishes of Sri Lankan 3D workers in South Korea. Gilbert (1978) stated, "For any given accomplishment, a deficiency in performance always has as its immediate cause a deficiency in a behavior repertory $(\mathrm{P})$, or in the environment that supports the repertory $(\mathrm{E})$, or in both. But its immediate cause will be found in a deficiency of the management system (M)" (p.76). According to Gilbert (1978) the ultimate reason for management is poor performance. BEM places the environmental supports to enhance positive behaviors to improve productivity so as performance.

Positive relationships and employers' attitudes towards their workers have positive impacts on employees' performance. Korean employers need to inculcate lasting relationships with their employees to gain profit from their labor. Having dinner parties, hiking, organizing cricket matches (sports meets) are some ways that employers can develop good relationships with their employees. It is suggested to have a positive attitude towards 3D workers reminding the history that Koreans worked as 3D workers in countries like Germany, Malaysia, Japan, and Saudi Arabia. It's necessary to ban the Korean concept of considering themselves as "us" and foreigners as "others." There must not be discrimination based on nationality, sex, and careers in Korea.

Due to the lack of training, language proficiency, and ignorance of Korean work culture, 3D foreign workers find it difficult to work and improve their performance. Sri Lankan government must provide extensive workplace training, better knowledge of Korean culture, work practices, technological knowledge, and safety. Training must be relevant and specific to the job.

Sri Lankan workers must be trained to cultivate positive attitudes and follow safety measures. They must not forget that they are in a foreign country; when you are in Rome, you must follow the Roman law. They must learn the Korean culture and language. Korean employers must treat employees equally, the reward for handwork, thus encouraging loyalty and remove the lances of discrimination. Employee motivation is imperative to achieve both employees and employers' dreams for success.

Korean government and ministry of labor can provide relevant training and service to these 3D workers irrespective of their nationality. It is recommended to erase prejudices towards 3D workers, irrespective of the level of expertise. All employees must be protected and treated as equal members. It is the Korean government officers' responsibility to protect all migrant workers from discrimination and enforce the law impartially without taking bribery. Authorities must treat 3D workers as humans who have their families' dependent on their salary and waiting impatiently until they come back. The hiring process of EPS must be unbiased and impartial.

Limitations and future research: This qualitative research is limited to 21 participants, and therefore, generalization is not our goal. Future research could focus on issues of South Korean migrant workers in separate sectors like manufacturing, production, and fishing. The Korean employers' attitudes towards 3D workers and as well as Korean people's perception of 3D workers are yet to be explored.

In conclusion, this study uncovers hidden realities that affect expatriate employee performance in South Korean workplace. The findings highlight the frictions, conflicts and cultural clashes between employers and employees in a host country workplace that diminish the performance of expatriate workers, thus hampering national goals of the country so as organizations and individual employees. The findings can be used to develop appropriate training and human resource development interventions for both employer and employees. 


\section{REFERENCES}

Abella, M. I., Park, Y. B., \& Böhning, W.R. (1994). Adjustments to Labor Shortages and Foreign Workers in the Republic of Korea. Geneva: International Labor Organization.

Ahmad, A. (2008). Dead men are working: Time and space in London's (Illegal) migrant economy. Work, Employment, and Society, 22(2), 301-18.

Albrecht, S.E. (2000). The effect of international business cross-cultural training on short term international business travel. (Doctoral dissertation, University of Central Florida, 2000). Dissertations Abstracts International, 61, 4067.

Anderson, B. (2010). Migration, immigration controls and the fashioning of precarious workers. Work, Employment and Society, 24(2), 300e317.

Arsene, C. (2014). Chinese employers and their Ugandan workers: Tensions, frictions a cooperation in an African City. Journal of Current Chinese Affairs, 1/2014, 139-176.

Binder, C. (2007). The six boxes, a descendant of Gilbert's behavior engineering model. Binder Riha Associates. Retrieved from www.sixboxes.com

Bogdan, R.C., \& Biklen, S.K. (2007) Qualitative Research for Education: An Introduction to Theory and Methods, (5th Edition). Allyn \& Bacon, Boston.

Cateora, P. R., Graham, J., \& Gilly, M.C. (2013). International marketing (16 ${ }^{\text {th }}$ ed.). New York, NY: McGraw Hill.

Carlson, D. S., Kacmar, M. K., Wayne, J. H., \& Grzywacz, J. G. (2006). Measuring the positive side of the work-family interface: Development and validation of a work-family enrichment scale. Journal of Vocational Behavior, 68(1), 131-164.

Collis, D., \& Montgomery (1995). Competing on resources: Strategy in the 1990s. Harvard Business Review, 73(July-August), 118-128.

Creswell, J. W. (2007). Qualitative inquiry and research design: Choosing among five approaches (2nd ed.). Thousand Oaks, CA, US: Sage Publications, Inc.

Crotty, M. (1989). The foundations of social research. London: Sage.

Curtis, S., \& Lucas, R. (2001). A coincidence of needs? employers and fulltime students. Employee Relations, 23(1), 38-54

Deadrick, D. L., \& Gardner, D. G. (1997). Distributional ratings of performance levels and variability. Group \& Organization Management, 22, 317-342.

Frendika, R., Sule, E. T., Kusman, M., \& Joeliaty (2018). Personal value versus cultural competency towards self-confidence through personal branding of employees between expatriates and local employees. Journal of Organizational Culture, Communications, and Conflict, 22(1), 1-7.

Garrod, B. (2005). Attitudes, personality, and behavior. McGraw-Hill International.

Gilbert, T. F. (1978). Human competence: Engineering worthy performance. New York: McGraw-Hill.

Green, J., \& Thorogood, N. (2004). Analyzing qualitative data. In: Silverman D. (eds.). Qualitative Methods for Health Research. London: Sage Publications, 173-200.

Gudykunts, W. B., \& Kim, Y. Y. (1992). Cultural values do correlate with consumer behavior. Journal of Marketing Research, 13,121.

Gungor, P. (2011). The Relationship between Reward Management System and Employee Performance with the Mediating Role of Motivation. Procedia Social and Behavioral Sciences, 24, 1510-1520.

Hammersley, M., \& Atkinson, P. (1995). Ethnography: principles in practice, (2 ${ }^{\text {nd }}$ edition). London: Routledge.

Harrell-Cook, G., Levitt, K., \& Grimm, J. (2017). From engagement to commitment: A new perspective on the employee attitude-firm performance relationship. International Leadership Journal, 9(1), 3-29.

Herbert, G. H., Donald, P. S., John, A. F., \& Lee, D. D. (2000). Personnel/Human Resource Management, (4th ed.). Universal Book Stall.

Hofstede, G., \& Bond, M. H. (1988). The Confucius connection: From cultural roots to economic growth. Organizational Dynamics, 16(4), 4-21. 
Holt, N., \& Sparkes, A. (2001). An ethnographic study of cohesiveness in a college team over a season, The Sports Psychologist, 15, 237-59.

Hyun-ju, O. (2017). Korea to accept 56,000 foreign workers in 2018. The Korea Herald. Retrieved from http://www.koreaherald.com/view.php?ud=20171222000777

Kim, M. J. (2017). The Republic of Korea's employment permit system (EPS): Background and rapid assessment. ILO, Geneva. Retrieved from

http://www.ilo.org/wcmsp5/groups/public/@ed_protect/@protrav/@migrant/documents/publicati on/wcms 344235.pdf

Kim, A. E. (2009). Global migration and South Korea: foreign workers, foreign brides, and the making of a multicultural society. Ethnic and Racial Studies, 32(1), 70-92.

Doi:10.1080/01419870802044197.

Kim, Y. (2017). Dire Work Conditions South Korea Migrant Workers (July 19, 2017). Retrieved from https:/www.koreaexpose.com/south-korea-migrant-workers/

Lofland, J., \& Lofland, L.H. (1995). Analyzing Social Settings: a guide to qualitative observation and analysis. Belmont, CA, Wadsworth Publishing Company.

Luthans, F., \& Stajkovie, A.D. (1999). Reinforce for performance: The need to go beyond pay and even reward. Academy of Management Executive, 13, 49-57

Malik, M. S., Awais, M., Timsal, A., \& Qureshi, U. H. (2016). Impact of ethical leadership on employees' performance: Moderating role of organizational values. International Review of Management and Marketing, 6(3), 590-595.

Martin, J., \& Nakayama, T. (2014). Experiencing intercultural communication: An introduction (5 ${ }^{\text {th }}$ ed.). New York, NY: McGraw Hill

Masson, J., \& Guimary, D. (1981). Asian labor contractors in the Alaskan canned salmon industry: 18801937. Labor History, 22(3), 377-397.

Madison, D. S. (2005). Critical ethnography: method, ethics, and performance. Thousand Oaks, Calif.: Sage.

McCloy, R.A., Campel, J. P., \& Cudeck, R. (1994). A confirmatory test of a model performance determinants. Journal of Appl. Psychology, 79, 493-854.

Merriam, S.B. (1998). Qualitative research and case study applications in education. Jossey-Bass Publishers, San Francisco.

Mines, R., \& Martin, P.L. (1984). Immigrant workers and the California citrus industry. Industrial Relations, 23(1), 139-149.

Muda, I., Rafiki, A., \& Harahap, M. R. (2014). Factors influencing employees' performance: A study on the Islamic banks in Indonesia. International Journal of Business and Social Science, 5(2), 73 80.

Najeeb, A. (2011). The status of migrant workers in the Maldives: 'Precarious workers' or 'labor aristocrats?'. Employment Relations Record, 11(2), 33-55.

National Human Right Commission of the Republic of Korea (2013). Retrieved from https:/www.humanrights.go.kr/site/program/board/basicboard/view?menuid=002003003001\&pa gesize $=10 \&$ boardtypeid $=7017 \&$ boardid $=7001821$

Noy, C. (2008). Sampling Knowledge: The Hermeneutics of Snowball Sampling in Qualitative Research. International Journal of Social Research Methodology, 11, 327-344.

O'Neil, D. (2006). What is culture? Retrieved from http://anthro.palomar.edu/culture/ culture_1.htm

Pak, Y. (2006). Multiculturalism matters: Learning from our past. Race and ethnicity in education: Principles and practices of multicultural education. Praeger: New York.

Park, C. K. (2007). The Analysis of major factors influencing on the divorce-intention of international marriage migrant women in Korean rural society. The Korean Rural Sociological Society, 17(2), 75-105 (In Korean).

Rozkwitalska, M. (2009). Cultural dilemmas of international management. Journal of intercultural management, 1(1), 91-99 
Saeed, R., Mussawar, S., Lodhi, R. N., Iqbal, A., Nayab, H. H., \& Yaseen, S. (2013). Factors affecting the performance of employees at workplace in the banking sector of Pakistan. Middle-East Journal of Scientific Research, 17(9), 1200 - 1208.

Seba, I., \& Rowley, J. (2010). Knowledge management in UK police forces. Journal of Knowledge Management, 14(4), 611-626.

Seol, D. H., Choi, H.Y., \& Han, G. S. (2002). Foreign workers' human rights in Korea. Seoul: National Human Rights Commission of Korea. (In Korean).

Seol, D. H., \& Han, G.S (2004). Foreign migrant workers and social discrimination in Korea. Harvard Asia Quarterly, 8(1), 45-50.

Seol, D.H. (2005). Global dimensions in mapping the foreign labor policies of Korea: A comparative and functional lysis. Development and society, 34(1),75- 124.

Truong, N. C. (2012). The impact of organizational factors on employees' performance in Vietnamese companies. Unpublished Research Report from Ho Chi Minh City.

Whetton, D. A., \& Kim S. Cameron. (1998). Developing management skills, New York: Addison-Wesley Educational Publishers Inc.

Wolcott, H. F. (1999). Ethnography: A way of seeing. Walnut Creek, CA: AltaMira.

Yi, S. (2013). Low-skilled labor migration: Korea's Employment Permit System Low-skilled labor migration: Korea's Employment Permit System. Retrieved from http://blogs.worldbank.org/peoplemove/low-skilled-labormigration-korea-s-employment-permit-system.

Yin, R.K. (2003). Case Study Research: Design and Methods. Sage, Thousand Oaks, California. 